\title{
TESTAMENTO VITAL: OS LIMITES E CONSEQUÊNCIAS JURÍDICO-PENAIS DO EXERCÍCIO DA AUTONOMIA EM FACE DAS DIRETIVAS ANTECIPADAS DE VONTADE
}

\section{Maria AuXILIAdora Minahim}

Doutora em Direito Penal pela Universidade Federal do Rio de Janeiro e doutora em Direito pela Universidade Federal do Paraná. Mestre em Direito Penal pela Universidade Federal do Rio de Janeiro. Professora Titular da Universidade Federal da Bahia.

Daniela Portugal

Doutora em Direito Público pela Universidade Federal da Bahia (UFBA/Edital 003/2010). Possui graduação em Direito pela Universidade Federal da Bahia (UFBA/2004-2008) e mestrado em Direito Público por esta mesma instituição (UFBA/2009-2011). É professora Assistente de Direito Penal da Faculdade de Direito UFBA.

\section{Resumo}

O presente artigo visa a analisar o testamento vital e suas consequências jurídico-penais. Adota como ponto de partida a autonomia e sua expressão no direito penal através do consentimento e, em seguida, na Resolução no 1.995 , de 2012, do Conselho Federal de Medicina. Posteriormente, examina a teoria do consentimento do ofendido e a possibilidade de a autorização da vítima funcionar como elemento excludente da tipicidade. Aborda os critérios disciplinados na Resolução, que regulamentam as diretivas antecipadas de vontade e os modelos de decisão substituta que adota. Em seguida, passa a tratar das consequências jurídico-penais para as diretivas antecipadas de vontade, especialmente aquelas que possam vir a abreviar a vida do paciente ou renunciar à sua protelação. Por fim, trata, especificamente, sobre a existência, ou náo, de um espaço para o consentimento presumido na matéria disciplinada pela Resolução.

\section{Palavras-chave}

Consentimento; Autonomia; Testamento vital.

\section{Abstract}

This article aims to analyze the living will and the legal consequences in criminal law. Takes as its starting point the treatment of autonomy under private law and then 
of Resolution n. 1.995, 2012, Federal Council of Medicine. Deals with the criteria disciplined in Resolution, regulating the living will and substitute decision models adopted. Then goes on to address the criminal law consequences for the living will, especially those that cause the patient's death. Later, examines the victim's consent theory and the possibility of the approval of the victim act as exclusive element of typicality. Deals with the criteria that are disciplined in the Resolution, which regulate the advance directives of will and substitute decision models adopted. Then goes on to address the legal and criminal consequences for the advance directives of will, especially those that may shorten the patient's life or abandon the postponement. Finally, specifically deals with the existence or not of a space for presumed consent in matters disciplined by Resolution.

\section{Key words}

Consent; Autonomy; Living will.

\section{Introdução}

A Resolução 1995, de 2012, do Conselho Federal de Medicina, reascende o debate acerca dos limites jurídicos ao exercício da autonomia humana, em especial quando a manifestação antecipada de vontade tiver como consequência a recusa a tratamento médico necessário à manutençáo da vida do paciente.

Normalmente, os debates jurídicos acerca do exercício da autonomia situam-se em extremos radicais que variam entre a defesa incomplacente do paternalismo estatal na tutela de bens jurídicos, ainda que contra a vontade expressa de seus titulares, e o culto extremo à autonomia individual, ignorando a solidariedade e a fraternidade no tratamento e cuidado para com a pessoa humana.

Difícil é encontrar um ponto de equilíbrio entre a consideração da vontade do indivíduo e a atenção ao poder/dever estatal de cuidado e proteção dos objetivos jurídicos resguardados pelo ordenamento, notadamente pelo sistema jurídico-penal. É esse o objetivo deste breve estudo: avaliar se há espaço para que as diretivas antecipadas de vontade interfiram na exclusão da responsabilidade penal daquele que cumpre a vontade do paciente, causando, todavia resultado definido como típico em legislação penal.

O que se propõe, portanto, é um diálogo dogmático, mas também crítico, entre o tratamento dispensado à autonomia pelo ordenamento jurídico e, mais especificamente, pelo Direito Penal, voltado a avaliar se há um espaço de compatibilidade entre a Resolução 1995, de 2012, e os critérios de exclusão de crime, nos termos do conceito analítico de delito.

Para tanto, inicialmente, será abordada a tutela da autonomia, destacando-se os diferentes modelos de decisão substituta - autonomia pura, julgamento substituto e melhores 
interesses. Neste sentido, intenta-se avaliar de qual dos referidos modelos se aproxima a pretensão do Conselho Federal de Medicina na disposição normativa estabelecida acerca do testamento vital.

Em seguida, trata-se, especificamente, da Resolução 1995, de 2012, do Conselho Federal de Medicina, quando serão examinadas as particularidades disciplinadas para a manifestação prévia do desejo do paciente quanto aos tratamentos e cuidados que desejará receber, ou não, no futuro. Observar-se-á, como recurso de interpretação imprescindível, a Resolução 1.805 de 2006, também do Conselho Federal de Medicina.

Posteriormente, busca-se examinar, a partir da teoria do consentimento do ofendido, a possibilidade de exclusão da tipicidade da conduta em virtude da autorização antecipada da prática de ortotanásia, evidenciando quais limites são aplicáveis à manifestação válida do consentimento presumido.

Por fim, analisa-se a relação entre as diretivas antecipadas de vontade e o Direito Penal brasileiro, indicando as normas penais aplicáveis à matéria no âmbito do sistema jurídico tradicional e, depois, a construção doutrinária do consentimento do ofendido aplicável ao testamento vital.

\section{A Tutela da Autonomia}

Tom Beauchamp e James Childress (BEAUCHAMP, 2002), ao trabalharem os princípios morais da bioética, afirmam a necessidade de respeito à autonomia (capacidade das pessoas para fazer escolhas livres de coação e de limitaçóes internas no âmbito da saúde); não-maleficência (a obrigação de evitar causar danos); beneficência (obrigação de proporcionar benefícios e equilibrar os benefícios e os riscos) e justiça (obrigação de equidade na distribuição dos benefícios e riscos). A autonomia, no tocante às diretivas antecipadas de vontade, destaca-se dentre os princípios a serem considerados no momento de avaliaçáo da vontade do paciente na busca por caminhos conciliáveis entre os avanços técnico-científicos e a proteção ao ser humano.

O século XXI, explica Romeo Casabona (2002, p. 284), é marcado pela necessidade de revisão dos valores sociais e princípios axiológicos em face dos novos conflitos relacionados às ciências biomédicas. Destaca o autor que, diante dos largos e apressados passos que conduzem o caminhar da ciência e da tecnologia, os novos fatos que se apresentam demandam, também, a ponderação sob uma nova ordem de valores adaptados às sociedades plurais nas quais não há existe uma visão única de bem comum. Deve caber, portanto aos sujeitos, a escolha do que consideram adequado, justo e bom para suas vidas.

Afirma Letícia Möller (2012, p. 82) que o termo autonomia corresponde à união do prefixo grego autos (próprio) e nomos (norma), de modo que é empregado como referência, 
atualmente, à autodeterminação, ao exercício do direito de liberdade e à possibilidade de realização de escolhas pessoais. Em sua origem, porém, estava ligado a uma dimensão política das polis gregas as quais, independentes, permitiam que seus cidadãos pudessem escolher as leis sob as quais seriam regidos.

Nesse sentido, nos termos definidos por Tom Beauchamp e James Childress, precursores da corrente principialista bioética, são elencados como elementos essenciais da autonomia a "liberdade (no sentido de independência de influências controladoras), a capacidade de entendimento e o agir intencionalmente", pensamento elaborado a partir das concepçôes de liberdade desenvolvidas por Immanuel Kant e John Stuart Mill (MÖLLER, 2012, p. 83).

Portanto, o princípio da autonomia impóe a necessidade de respeito à capacidade individual de decisão do ser humano, para que este decida de acordo com o direcionamento que pareça melhor para si, elaborado a partir de sua vontade e de suas crenças pessoais (SANTORO, 2012, p. 101).

Quanto ao exercício de vontade autônoma do paciente, deve ser reconhecido o seu direito de poder controlar sua vida e intimidade, não se podendo opor à sua vontade individual o desejo de outra pessoa, ainda que de um médico, sendo-lhe facultadas a "escolha do médico e da adoção da medida terapêutica, segundo as próprias convicções, após ter recebido e compreendido as informaçôes necessárias para a manifestação de sua vontade" (SANTORO, 2012, p. 101).

Especificamente quanto ao direcionamento a ser dado no que diz respeito às medidas terapêuticas a serem utilizadas em tratamento médico, torna-se premente a necessidade de balizar os novos conflitos éticos, especialmente aqueles verificados diante da impossibilidade de manifestaçáo presente de vontade do paciente, a partir dos diferentes modelos de decisão substituta desenvolvidos por Tom Beauchamp e James Childress (2004).

Monica Aguiar (2013, p. 212) explica os diferentes paradigmas construídos pelos referidos autores, tratando dos modelos da autonomia pura, do julgamento substituto e dos melhores interesses. Sobre o modelo da autonomia pura, explica a autora que "é engendrado como forma de manter incólume a vontade real que a pessoa haja manifestado quando ainda capaz", somente se aplicando para os casos em que o próprio indivíduo, antecipadamente e em pleno estado de capacidade, declara, expressamente, a sua vontade.

Desta maneira, trata-se da mais clara forma de imposição de limites à intervenção médica não curativa, dando ao paciente o poder de optar, antecipadamente, pelos tratamentos que lhe são convenientes, instrumento especialmente útil à manifestação de vontade para o futuro, caso sobrevenha, a este paciente, um estado de inconsciência (FREIRE DE SÁ; MOUREIRA, 2012, p. 183). 
O modelo de julgamento substituto, diferentemente, apenas tem lugar quando o próprio paciente não pôde declarar a sua vontade, de forma o sujeito que decidirá em seu lugar, como forma de respeito à autonomia do paciente, deverá escolher com base não em seus valores pessoais, mas nos do próprio incapaz (SILVA, 2013, p. 2012).

Já o modelo dos melhores interesses, muito embora também verificado somente quando o próprio paciente não é capaz de manifestar expressamente sua vontade, caracteriza-se, peculiarmente, pelo fato de a escolha do decisor ser pautada "tomando como parâmetros os benefícios e riscos para o paciente", de acordo, portanto, "com o que considera seja a alternativa que traga o maior benefício e o menor risco possível" (SILVA, 2013, p. 2012). Esse modelo está ligado ao paternalismo na medicina, quando os médicos supunham-se no direito de fazer a melhor escolha para o paciente, muitas vezes contra o próprio desejo deste, por serem mais bem informados do que ele quanto às questóes relativas à preservação da vida e da saúde.

Para Mônica Aguiar, na Resolução 1995, de 2012, “o modelo por excelência escolhido pelo conselho profissional foi, efetivamente, o da autonomia pura", extraído a partir do art. $1^{\circ}$ e do art. $2^{\circ}$, caput, da Resolução, admitindo, todavia, a adoção subsidiária dos modelos do julgamento substituto e dos melhores interesses a partir das disposiçóes encontradas nos $\$ 1^{\circ}$ e $2^{\circ}$ do art. $2^{\circ}$ do mesmo diploma normativo (2013, p. 2012).

Outra referência normativa importante à autonomia, razão pela qual merece destaque, é a previsão inscrita no art. 15 do Novo Código Civil brasileiro, que dispóe: "Ninguém pode ser constrangido a submeter-se, com risco de vida, a tratamento médico ou a intervenção cirúrgica”, o que se coaduna o art. 53 do Código de Ética Médica, que veda ao médico o ato de "desrespeitar o interesse e a integridade de paciente, ao exercer a profissão em qualquer instituição na qual o mesmo esteja recolhido independentemente da própria vontade”.

De acordo com Tom Beauchamp (2003), a autonomia como base principiológica da bioética ganha especial destaque no exame da manifestação de vontade dos pacientes, no caso específico comentado pelo autor sobre as Testemunhas de Jeová que recusam o procedimento de transfusão sanguínea. Destaca o autor que, em tal caso, conflitam duas regras morais básicas: a) é moralmente proibido submeter a risco de morte um paciente cuja condição de vida pode ser administrada por técnicas médicas adequadas; b) é moralmente proibido desrespeitar uma recusa de tratamento.

Como forma de compatibilizar as duas regras morais conflitantes, Tom Beauchamp (2003) elabora que é moralmente proibido desrespeitar uma recusa de tratamento pelo paciente, a menos que a recusa não seja autônoma e que represente um perigo significativo para o paciente. De acordo com o autor nota-se, portanto, que o respeito à autonomia como base ética na condução do tratamento do paciente mantém-se essencialmente intacto, pois 
se, de um lado, estabelece que o médico não é absolutamente obrigado a respeitar as recusas de tratamento, deixa claro, de outro lado, que o leque de exceçóes é estreito.

Por esta razáo, que o autor admite o respeito à autonomia de pacientes adultos e capazes na recusa a tratamento, independente das consequências, mas não estende o mesmo posicionamento, por exemplo, quanto à recusa parental de tratamento para menor incapaz, sob o fundamento de que, se a morte da criança é evitável, não se poderá permitir que esta seja provocada em nome de um ato de negligência, abuso, ou convicção religiosa de seus pais (BEAUCHAMP, 2003). Como não há, em tais casos, manifestação de vontade autônoma por parte da criança, deve-se garantir a prevalência à evitabilidade da morte.

Deve-se, destacar, todavia, que o conceito de autonomia em bioética não coincide com o de capacidade em direito porque se postula que mesmo os menores possam participar das decisóes sobre as intervençóes em seu corpo. Naturalmente, deve-se ter em consideração sua aptidão de compreensão em face da complexidade de cada caso. Da mesma forma, o respeito à autonomia pretende que doentes mentais, também na medida de sua percepção e consciência, possam tomar parte nas deliberaçóes sobre providências terapêuticas que lhes digam respeito.

É preciso que se reafirme, porém que a capacidade de autodeterminação não pode ser compreendida como a liberdade irrestrita de ação, uma vez que a ideia de sociedade e de direito envolve também a de restriçóes, auxílios e renúncias em favor do coexistência do grupo enquanto tal. Kottow $(2007$, p. 27) alerta para os excessos quanto à celebração da autonomia, sobretudo quanto ao prejuízo para a formaçáo de pensamentos éticos em comum que permita a geração de consensos. Adverte, de outro lado, que apesar dos efeitos negativos e indesejados, a autonomia continua como o suporte ético mais destacado na proteção dos pacientes.

Percebe-se, diante dos novos conflitos que são objeto de reflexão da bioética, o quão importante é o tratamento da autonomia, especialmente a delicadeza e complexidade de reconhecê-la nos casos em que o paciente não é capaz de manifestar, autonomamente, sua vontade, no exato momento em que se decide qual tratamento deve vir a ser adotado. Neste caso, cumpre tratar do regramento jurídico que o conselho Federal de Medicina dispôs acerca das diretivas antecipadas de vontade, buscando minimizar a lacuna jurídica que se tinha diante da matéria, e compatibilizando a base ética de respeito à autonomia do paciente com a excepcional possibilidade de recusa à vontade manifestada.

\section{0 Consentimento do Ofendido como Expressão de Autonomia}

No Direito Penal, o consentimento do titular do bem jurídico tem sido o instituto que mais diretamente expressa o respeito à autonomia de uma pessoa, muito embora encontre limitaçóes quanto ao seu exercício. Explica José Henrique Pierangeli (2001, p. 72) 
que "consentimento" encontra sua origem etimológica no latim, na palavra "consentire", como forma de exprimir uma situaçáo de concordância entre as partes ou de uniformidade de opinião.

Há importantes extensôes no campo do Direito Penal em favor da autonomia da vítima, porém, nem todas elas são forma ou expressão do consentimento, a exemplo da autolesão e da heterolesão consentida, da contributory negligence e da imputação ao âmbito de responsabilidade da vítima, por exemplo. Ocorre, entretanto que sua natureza, consequências e posição sistemática na estrutura do delito são distintas, o que não cabe minudenciar no corpo deste trabalho. Pode-se dizer, como o faz Manoel da Costa Andrade, (1991, p. 291) que as construções retrocitadas são baseadas em "uma aproximação meramente fenomenológica e privilegia os modelos de interação delinquente vítima”, enquanto o consentimento destaca a vontade do autor em afastar a proteção normativa.

As origens do consentimento estão baseadas em Ulpiano: volenti non fit iniuria (frente a aquele que assente, não há lugar para nenhum injusto), embora tal máxima tenha vindo a sofrer restriçóes ao longo da história. As limitaçôes foram opostas, sobretudo para balizar a força do consentimento em operar o afastamento da proibição, de forma que, em se tratando de bens jurídicos indisponíveis, tais como a vida, a saúde e de bens jurídicos coletivos, a vontade do titular perde sua força no campo normativo (ROXIN, 1997. p. 526)

A doutrina costuma distinguir as formas de aquiescência (gênero) entre acordo e consentimento, o que tem diferentes consequências, seja na posição sistemática que deve ocupar na teoria do delito, seja na consequente responsabilização do autor da açáo, falando-se, então, em autores dualistas e monistas.

Roxin (1997, p. 517) é um dos principais defensores da corrente monista, sustentando que a liberdade de ação do sujeito consenciente consiste em fundamento legítimo para a exclusão do tipo penal. $\mathrm{O}$ autor parte de uma premissa de orientação liberal para a compreensão do bem jurídico, asseverando que, se os bens jurídicos são criados para servir ao livre desenvolvimento do indivíduo, náo se pode falar em lesão a bem algum quando o comportamento se funda em um ato de disposição do seu titular.

Significa dizer que a lesão consentida a um bem ao revés de corresponder a um ato de dano a bem jurídico, representa, ao contrário, sua constituição à luz da vontade do próprio titular. Deste modo, o consentimento emana da liberdade de desenvolvimento da personalidade do portador do bem, inexistindo razóes para que se fale, diante de casos tais, em lesão. $\mathrm{O}$ ato de manifestação de vontade, seguindo esta perspectiva liberal, corresponde a uma faculdade de disposição do titular do bem jurídico, cabendo ao estado tolerar o seu livre exercício. Coerentemente com esses enunciados, apenas trabalha com o conceito de consentimento, compreendendo este como causa de exclusão da tipicidade 
da conduta. Inobstante a postura liberal, Roxin (1996, p. 526), compreende que há bens jurídicos indisponíveis dentre os quais a vida.

Já para os dualistas, o acordo funciona como causa de exclusão de tipicidade enquanto o consentimento, como causa de exclusão da ilicitude.

Compreendendo, melhor o pensamento dualista, fala-se em acordo diante da concordância do titular do bem jurídico com um comportamento cujo tipo penal correspondente contém o dissenso da vítima como uma de suas elementares típicas. É o caso, de um modo geral, dos tipos penais de constrangimento - em tais hipóteses, havendo completa anuência da vítima para a realização da conduta, deixa de existir o próprio ato de constranger, tratando-se, portanto, de conduta atípica.

Ainda segundo o pensamento dualista, é possível referir-se a consentimento quando o tipo penal incriminado não faz menção ao dissenso da vítima como uma de suas elementares essenciais, de maneira que o consentimento desta será irrelevante para o afastamento da tipicidade da conduta, podendo unicamente, conforme o caso (bem jurídico disponível ou consentimento presumido) afastar a ilicitude.

Manoel da Costa Andrade (1991, p. 190-191) é partidário do pensamento dualista, diferenciando consentimento de acordo em matéria penal. Na compreensão do autor, entre o modelo tradicional dualista que distingue acordo e consentimento e a proposta de unificação doutrinal do consentimento penalmente relevante, há que se observar o fato de a proposta de unificação estar construída à custa de um encurtamento de distâncias indevido entre o acordo que exclui o tipo e o consentimento que justifica o ilícito. Sustenta, portanto que há casos de anuência nos quais a relação não se extingue entre o que consente e o que recebe o consentimento, mas atinge também o sistema social, o que pode ser fonte eventual de "frustração e conflito", a exemplo das demais causas de exclusão de antijuridicidade.

No âmbito do Direito Penal brasileiro, segue-se, majoritariamente, a posição dualista, entendo-se que o acordo afasta a tipicidade e o consentimento em sentido estrito exclui a ilicitude. Para a configuração do acordo, é indispensável que o tipo penal descreva uma violação da vontade do titular do bem jurídico, como já visto, a qual deixará de existir com a mera manifestação de sua vontade natural. É exemplo dos mais referidos o da violação de domicílio, no qual o injusto reside no dissenso do titular do bem jurídico, como é expressamente previsto pela lei penal brasileira no artigo 150 do Código Penal brasileiro.

O consentimento do ofendido assume a natureza de causa supralegal de exclusão da ilicitude, vinculando, de um modo geral, o efeito justificante da manifestação de vontade do titular às seguintes condiçôes: a) bem jurídico disponível; b) sujeito consenciente capaz; c) consentimento anterior ou concomitante ao ato lesivo; d) consciência, por parte de quem pratica o ato lesivo, da existência de consentimento dado pelo titular do bem; e) 
inexistência de vícios de vontade no ato de consentir; f) consentimento que não contrarie a moral e os bons costumes.

Muitos países preferiram incluir um dispositivo na legislação criminal, dispondo sobre o consentimento, em razão da particular importância da autonomia sobretudo na matéria da relação médico paciente e na manifestação da autonomia deste último.

O Código Penal português (1995) trata do consentimento do ofendido a partir do seu art. 38, estabelecendo como regra geral, fora dos casos especialmente previstos em lei, que o consentimento excluirá a ilicitude, desde que se refira a interesses jurídicos livremente disponíveis e que não ofenda os bons costumes. Estabelece, ainda, que o "consentimento pode ser expresso por qualquer meio que traduza uma vontade séria, livre e esclarecida do titular do interesse juridicamente protegido, e pode ser livremente revogado até à execução do facto". Quanto à capacidade do titular, o referido dispositivo ainda estabelece que a eficácia do consentimento depende de ser o sujeito consenciente, maior de 14 anos e possuir o discernimento necessário para avaliar sua manifestação de vontade.

Há uma inversão de ideias, porém quando se trata de consentimento presumido construção que permite a intervenção em emergências médicas e em situaçóes nas quais não é possível a obtenção do consentimento. Nesses casos, não havendo dados objetivos que permitam deduzir que o paciente recusaria a intervenção, o médico pode intervir em favor da vida e da saúde. Trata-se, na hipótese de causa de exclusão da ilicitude para ambas as correntes já que a vontade que foi deduzida pode não ter sido a verdadeira.

Assim procede o Código português, quando se refere ao consentimento presumido para permitir a intervenção médica quando não houver consentimento expresso: inverte o pressuposto do artigo 38, dispondo no artigo 156 que há consentimento presumido se "não se verificarem circunstâncias que permitam concluir com segurança que o consentimento seria recusado". Ou seja, assume uma posição frontalmente pro vida, impedindo que, o desconhecimento da posição do paciente, imobilize o socorro médico necessário.

Já o Código Penal Alemão (1871/1998), muito embora não estabeleça um regramento geral sobre a matéria, ao tratar da lesão corporal com resultado morte, disciplina, no $\$ 228$, que o consentimento afastará a antijuridicidade do comportamento ofensivo, desde que este não ofenda aos bons costumes. Além disto, pune, no $\$ 216$, o homicídio a pedido do paciente com pena de até cinco anos, não conferindo à vontade da pessoa eficácia jurídico-penal outra que a da mitigação da pena. Tem-se entendido, ademais, que os atentados contra vida e a saúde não são legitimados pela anuência do portador do bem jurídico, o que se constata pelas decisóes do BGH, que se manifesta a favor da indisponibilidade desses bens (ANDRADE, 1991, p. 303)

Em face às posiçóes divergentes, cabe examinar, o testamento vital à luz da teoria do consentimento, isto é, examinando se é possível reconhecer a justificação da conduta 
terapêutica lastreada em diretiva antecipada de vontade, e quais seriam, nesse caso, os limites ao reconhecimento da validade do consentimento presumido do paciente.

\section{A Resolução 1995, de 2012, do Conselho Federal de Medicina: as Direti- vas Antecipadas de Vontade}

Ao contrário do testamento civil, que tem por objeto, nos termos do art. 1.857 do Código Civil, o ato de disposição do testador de totalidade ou parte dos seus bens, para depois de sua morte, o "testamento vital" aponta sua eficácia para o próprio curso da vida do testador, que irá indicar de que forma desejará "ser tratado - do ponto de vista médico - se estiver em uma situação de doença grave e inconsciente” (LIPPMANN, 2013, p. 17).

A terminologia “testamento vital", todavia, é criticada sob o fundamento não só de que a eficácia das diretivas antecipadas de vontade está voltada ainda para o curso da vida do paciente, como também de que não são necessárias as mesmas formalidades exigidas para o testamento post mortem (FREIRE DE SÁ; MOUREIRA, 2012, p. 184).

A despeito da usual terminologia "testamento vital", a Resolução 1995, de 31 de agosto de 2012, faz menção expressa à expressão "diretivas antecipadas de vontade" como referência à manifestação prévia do conjunto de desejos expressamente manifestados pelo paciente sobre os cuidados e tratamentos que quer ou náo receber caso venha a se encontrar em situação incapacitante de manifestação livre e autônoma de sua escolha.

A Resolução leva em consideração, dentre outros elementos, a relevância dada à autonomia do paciente na contemporaneidade e a necessidade de fornecer, ao médico, orientação nos casos em que haja manifestação de vontade no sentido de abstenção de procedimentos. Tal situação tem expressiva importância no plano ético e jurídico, mas, não obstante, ainda não é disciplinada no ordenamento jurídico nacional.

É nesse sentido que as diretivas antecipadas de vontade buscam orientar o tratamento do paciente, de modo que a vontade por este expressa, antes da vivência da situação incapacitante, possa ser levada em conta quando da escolha do tratamento adequado.

Por tal razão, o art. 20 da Resoluçáo consagra a atenção preferencial à manifestação autônoma de vontade do paciente ao estabelecer que, "nas decisóes sobre cuidados e tratamentos de pacientes que se encontram incapazes de comunicar-se, ou de expressar de maneira livre e independente suas vontades, o médico levará em consideração suas diretivas antecipadas de vontade".

Muito embora seja manifesta a opção do Conselho Federal de Medicina pela prevalência do modelo da autonomia pura, consoante fica evidente no mencionado dispositivo, não se trata do único modelo ponderado na Resolução. Esta também registra, no art. 2º $\$ 1^{\circ}$, a possibilidade de o paciente designar um representante para o fim de manifestaçáo 
de um julgamento substituto diante da impossibilidade de manifestação expressa do desejo do próprio titular do direito. Além disso, ainda afirma, no $\$ 2^{\circ}$, a possibilidade de o médico deixar de "levar em consideração as diretivas antecipadas de vontade do paciente ou representante que, em sua análise, estiverem em desacordo com os preceitos ditados pelo Código de Ética Médica”.

É dizer, portanto, que, nem mesmo nos moldes da própria Resolução 1995, de 2012, que homenageia, notadamente, o dever de respeito à manifestaçáo autônoma de vontade do paciente, esta autonomia pode ser exercida de forma irrestrita e ilimitada, devendo ser ponderada, portanto, com os princípios disciplinados no Código de Ética Médica - Resolução CFM no 1.246/88.

A título de exemplo, cita-se a previsão do art. 28 do Código de Ética Médica, que consagra o direito fundamental do médico de se recusar a praticar determinados atos, ainda que permitidos em lei, quando estes forem contrários aos ditames de sua consciência. Imagine-se então um médico pessoalmente contrário à prática da ortotanásia que venha a tratar de paciente que, em suas diretivas antecipadas de vontade, solicita-lhe o emprego da referida prática - poderá o médico deixar de atender à vontade do paciente, nos termos do art. 2º, $\$ 2^{\circ}$ da Resolução 1.995/2012, bem como do art. 28 da Resolução no 1.246/88, sem prejuízo de outro profissional vir a realizá-la.

Diante de um paciente incapaz de manifestação autônoma de vontade, sobretudo, aquele em estágio terminal, a atitude médica deve ser pensada com extrema cautela, levando-se em conta que os caminhos possíveis devem compatibilizar, sempre, a proteção à vida e o respeito à autonomia do paciente.

Outro aspecto que merece reflexão na análise da Resolução suprarreferida diz respeito à validade temporal do documento. Miguel Reale Junior (2013, p. 2) questiona o período durante o qual se deve considerar eficaz a manifestação da vontade feita pelo declarante. É possível, por exemplo, que o testamento vital tenha sido feito quando a pessoa tinha quarenta ou cinquenta anos, seriam ainda verdadeiras aos setenta, oitenta anos, as declaraçóes nele contidas? Não se pode desconsiderar que a proximidade da morte possa fazer com que a pessoa tenha outra posição com relação ao tema, razão pela qual aquele autor recomenda que seja o testamento renovado a cada cinco anos de forma que possa refletir a vontade atual do paciente.

No que diz respeito à forma, o mesmo Miguel Reale (2013) questiona se basta uma declaração simples, ou se ela deve ser feita diante de testemunhas, ou, ainda, se o documento deve ser feito em cartório. A Resolução é pouco formalista quanto a este aspecto, prevendo que as diretivas antecipadas possam, até mesmo, ser registradas no prontuário do paciente pelo médico a seu pedido.

Não fica evidente, tampouco, se a declaração pode ser cumprida por qualquer médico, inclusive o profissional liberal que assista ao paciente em sua residência, entendo-se 
que não, apenas em razão do artigo 5º, da Resolução 1.995/2012, o qual refere que, em casos de dúvidas ou falta de consenso, o médico recorrerá ao "Comitê de Bioética da instituição, caso exista, ou, na falta deste, à Comissão de Ética Médica do hospital ou ao Conselho Regional e Federal de Medicina para fundamentar sua decisão sobre conflitos éticos".

O âmbito de validade das decisôes tomadas pelo paciente nas diretivas antecipadas de vontade é a questão que demanda maior precisão do interprete da Resolução 1.995 de 2012, porque sua repercussão atinge bem jurídicos tradicionalmente indisponíveis, quais sejam vida e integridade física. O legislador administrativo teve o cuidado de, logo nos considerando, indicar o limite de produção de efeitos dele esperado quando afirma que "os novos recursos tecnológicos permitem a adoçáo de medidas desproporcionais que prolongam o sofrimento do paciente em estado terminal, sem trazer benefícios, e que essas medidas podem ter sido antecipadamente rejeitadas pelo mesmo" (CFM, 2012). A interpretação da expressão "medidas desproporcionais", em face dos tradicionais conceitos de eutanásia e ortotanásia, já encaminha no sentido da compreensão de que se trata de hipótese da segunda, qual seja, ortotanásia.

Assim é que, apenas para relembrar, na breve definição de Mônica Silveira Vieira (2012, p. 103), entende-se a eutanásia "como a conduta que, ativa ou passivamente, mas sempre de forma intencional, abrevia a vida de um paciente, com o objetivo de pôr fim ao seu sofrimento". Já a ortotanásia, de acordo com Maria Elisa Villas-Bôas, corresponde à morte em seu tempo certo, (orthos = reto, correto), verificando-se quando o médico deixa de interferir "no momento do desfecho letal", nem antecipando, nem prolongando a vida do paciente (2005, p. 73).

A autora alerta para a habitual e equivocada confusão entre ortotanásia e eutanásia, tratadas, por alguns autores, como espécies sinônimas, apontando, como critério distintivo, o fato de a eutanásia envolver, necessariamente, uma antecipação da morte, o que não ocorre na ortotanásia (VILLAS-BÔAS, 2005, p. 73). A distanásia, diferentemente das duas outras espécies, pode ser compreendida como "o prolongamento artificial da vida que, naturalmente, já atingira o seu declínio e que, sem manobras médicas, já estaria finda", buscando-se "preservar a vida de qualquer maneira, mantida à custa de muito sofrimento” (GUIMARÁES, 2011, p. 134-135).

Uma análise da Resolução 1.805 de 2006, como se disse, é bastante esclarecedora no sentido de que a possibilidade de disposição do paciente está restrita aos casos de enfermidade grave e incurável, em fase terminal, e ao uso de recursos desproporcionais, conforme está disposto no artigo primeiro. A segunda Resolução, a 1.995 de 2012 é, portanto, a extensão da possibilidade de expressão de consentimento àquele que, temendo no futuro vivenciar uma situação clínica que o impeça de expressar a mesma anuência, possa fazê-lo antecipadamente. Portanto, não consagra a legitimação da eutanásia no ordenamento 
nacional até porque, na primeira normativa, está previsto o respeito aos preceitos ditados pelo Código de Ética. Ora, se o médico pode náo acatar a decisão do doente quando esta afronta o código deontológico, mais razóes terá para abster-se da conduta desejada quando esta se opuser ao Código Penal.

Nos Estados Unidos, entende-se, corretamente, que estão excluídas do alcance das diretivas as equipes médicas de emergência e prestadores de serviços ambulatoriais. Nesse país, o PSDA (Patient Self-Determinatio Act) foi aprovado em 1991, prevendo a possibilidade de recusa à alimentação e hidratação por meio de sondas, situação que não é pacífica em outros países. Argui-se ainda que estudos demonstram que não se fornecem informaçôes suficientes, nem se avalia se o doente, de fato, compreende o conteúdo do que autorizou (POPE, 1999).

Na França, o Código de Saúde Pública prevê, expressamente, art. 11111-11, que qualquer adulto pode escrever suas diretivas antecipadas de vontade, para o caso de, um dia, tornar-se incapaz de manifestar a própria vontade. O referido dispositivo ainda estabelece que o médico considere a vontade do paciente para qualquer intervençáo ou tratamento, desde que tenham sido estabelecido há menos de três anos antes de estado inconsciente da pessoa.

A Argentina, em 9 de maio de 2012, sancionou a Lei no 26.742, que altera, dentre outros dispositivos legais, o art. 11 da Lei no 26.529, passando a prever que toda pessoa capaz e maior de idade pode dispor de diretivas antecipadas, podendo consentir ou rechaçar determinados tratamentos médicos, bem como demais decisóes acerca de sua saúde. A previsão, todavia, ressalva, expressamente, eventuais autorizaçôes à prática de eutanásia - ocasião em que as diretivas antecipadas serão tidas como inexistentes. Além disso, o art. 60 do Novo Código Civil e Comercial argentino, a entrar em vigor em 01 de janeiro de 2016, aborda, especificamente, as diretivas antecipadas de vontade, mantendo a mesma ressalva com relação às diretivas que autorizem a prática de eutanásia.

Outro regramento jurídico que merece destaque é o do México. O Decreto no 82, de 03 de maio de 2013, disciplina a declaração de vontade antecipada de forma minuciosa. $\mathrm{O}$ art. 30, inciso III, estabelece que a diretiva será nula quando contemplar pedido para provocação intencional da morte ou de suicídio assistido, fazendo referência, inclusive, às consequências assinaladas no Código Penal mexicano.

No Brasil, em que pese tenha sido a matéria regulamentada, o tratamento das diretivas antecipadas de vontade por meio de Resoluçáo do Conselho Federal de Medicina foi judicialmente contestado. O Ministério Público Federal de Goiás, em janeiro de 2013, ajuizou a Ação Civil Pública no 0001039-86.2013.4.01.3500, fundamentada na inconstitucionalidade da Resolução 1.995/2012. Argumentou-se, dentre outras razóes, que a Resolução extrapola os limites conferidos pela Lei no 3.268/1957, que dispóe sobre as 
atribuiçóes dos conselhos de Medicina; além disso, alegou-se que somente a União, por meio do Congresso Nacional, poderia tratar da matéria, consoante estabelece o art. 22 da Carta Constitucional (TRIBUNAL REGIONAL FEDERAL DA PRIMEIRA REGIÁO, 2014).

Tanto a decisão liminar, publicada em 2 de maio de 2013, quanto em caráter definitivo, publicada em 2 de abril de 2014, afirmaram a constitucionalidade da Resolução $1.995 / 2012$, cabendo destacar que, em fundamentação, destacou-se que o assunto, preferencialmente, deve ser tratado por lei em sentido estrito, todavia, diante do vazio legislativo, o Conselho Federal de Medicina não estaria extrapolando suas atribuiçóes, o que não impediria que a família ou mesmo o poder público buscassem tutela judicial a fim de afastar a eficácia das diretivas antecipadas de vontade firmadas pelo paciente incapaz (TRIBUNAL REGIONAL FEDERAL DA PRIMEIRA REGIÃO, 2014).

Note-se, portanto, que o testamento vital representa matéria cujo debate se apresenta de extrema urgência, não só quanto aos limites éticos relacionados à relação entre o médico e o seu paciente, como também acerca de seus limites jurídicos. Portanto, o exercício da autonomia encontra-se limitado não só no próprio Código de Ética Médica, como também por outros diplomas jurídicos - destacando-se, no presente estudo, o Código Penal brasileiro.

\section{O Direito Penal e o Testamento Vital}

Diferentemente do Código Civil e da Resolução CFM 1.995/2012, o Código Penal não estabelece, em sua Parte Geral, um tratamento específico para o exercício da autonomia. Quanto à proteção de bens jurídico-penais, entende-se que o interesse de tutela ultrapassa a esfera individual, atraindo o poder/dever de proteção estatal contra eventuais ataques. É de acordo com esta concepção paternalista que o Código Penal brasileiro não estabelece, em seu texto, nenhuma consequência jurídica geral justificante para o consentimento do ofendido.

Assim, dada à ausência de norma penal permissiva expressa, ainda que a lesão a um indivíduo tenha sido por este autorizada, o Estado ignora este livre exercício autônomo de vontade em prol do exercício do ius puniendi, do qual náo pode se afastar quando da ocorrência de lesão ou perigo concreto de lesão aos bens jurídicos considerados indisponíveis que compóem o âmbito criminal de tutela. A omissão da lei não impediu a doutrina construir as bases do instituto e os tribunais de convocá-lo nas situaçóes admitidas pelo direito brasileiro, quais sejam bens disponíveis e o dissenso como elemento do tipo. $\mathrm{Na}$ primeira hipótese, cuida-se de causa supralegal de exclusão da ilicitude.

O afastamento da ilicitude positivado não ultrapassa as hipóteses, nos termos do art. 23 do Código Penal, quando o agente atua em estado de necessidade; legítima 
defesa; estrito cumprimento de um dever legal ou no exercício regular direito. Comportam também a exclusão de antijuridicidade as formas de aborto previstas no artigo 128. O art. 121, $\$ 3^{\circ}$, do Anteprojeto da Parte Especial do Código, de 1984, chegava a prever, de forma inédita na legislação brasileira, uma isenção de pena para o "médico que, com o consentimento da vítima, ou na sua impossibilidade, de ascendente, descendente, cônjuge ou irmão, para eliminar-lhe o sofrimento, antecipa morte iminente e inevitável atestada por outro médico" (SOUSA, 1994, p. 287).

A referida mudança, entretanto, não foi introduzida no Código Penal brasileiro, tendo prevalecido o entendimento de Nelson Hungria (1954, p. 14) a respeito da matéria, para quem, mesmo quando houvesse a comovente súplica de morte formulada pela própria vítima, desenganada diante de doença grave e irreversível que provoque grande sofrimento, o atendimento ao pedido jamais deixaria de ter um fundo egoístico, em que o terceiro visa a se libertar, em última análise, de sua própria angústia. Tal entendimento resulta do fato de que, no Brasil, o bem jurídico protegido pelo Direito Penal é a vida e não a qualidade de vida do indivíduo, de forma que, mesmo terminal, caso se ministre uma injeção letal no paciente, haverá eutanásia punível.

É bem verdade que o Código Penal vigente não trata nem de eutanásia - matéria estranha à resolução como se disse - nem de ortotanásia, ou seja, da renuncia a intervençóes que causem mais sofrimentos que benefícios. Na prática, porém, médicos têm acordado com o doente e a família sobre os caminhos a percorrer quando se tratar de enfermidade em estágio terminal, diante da qual as intervençóes possíveis são desproporcionais e o paciente manifeste sua vontade em receber cuidados paliativos apenas.

O Projeto de Código Penal prevê a ortotanásia como causa que exclui a ilicitude quando, deveria, na verdade, em homenagem à autonomia, ao consentimento dado pelo paciente, em situação estritamente delimitada, admitir tratar-se de exclusão de tipicidade, tornando a situação um indiferente penal, tanto obstando tanto a instauração de inquérito policial, como o oferecimento de denuncia. A persistir tal posição, embora o profissional aja com todos os cuidados exigidos pela Resolução, ainda assim poderia estar sujeito a um procedimento penal caso a autoridade policial, indevidamente, mas costumeiramente, entenda estar diante de possibilidade de ocorrência de um delito. Isto porque a força indiciária de situação fática, típica, porém lícita, é superior à daquela que se considere atípica de plano. Esta é uma das razóes pela qual não se trata de debate puramente dogmático, mas também instrumental na garantia processual do destinatário do consentimento.

Para um sistema que pretende até mesmo suprimir a incriminação da eutanásia, que implica em antecipação da morte, remetendo o tema para o direito civil e para o direito administrativo, trata-se, no mínimo, de incoerência jurídica e ética. Se o mais não 
é considerado conduta típica, não há porque dispor sobre menos como causa de exclusão de ilicitude, apenas (COMISSÃO TEMPORÁRIA DE ESTUDO DA REFORMA DO CÓDIGO PENAL, 2013). A ser aprovado na atual formatação, o Brasil será o quarto país no mundo a admitir a eutanásia, prática que sofre restriçóes dos grandes autores contemporâneos, a exemplo de Claus Roxin, conforme visto supra (1997. p. 526).

Diante de tais elementos, note-se que o testamento vital, ainda que se entenda estar respaldado no regramento normativo dado pelo Conselho Federal de Medicina, ou mesmo que se admita encontrar amparo no tratamento da autonomia dispensado no art. 15 do Código Civil brasileiro, pode vir a encontrar, no futuro Código Penal brasileiro, obstáculos. Isto porque, partindo de uma interpretação literal da norma penal estabelecida, mesmo a autorização expressa, livre e consciente de um paciente capaz à prática de um ato médico que venha a lhe causar lesão ou morte não terá o efeito jurídico de exclusão legal da tipicidade.

De outro lado, a prática de intervençôes desnecessárias e que causem apenas sofrimento podem ser reconhecidas como lesão corporal, porque embora o Brasil não disponha de uma Lei de Autonomia, a exemplo de outros países, os procedimentos não autorizados podem configurar o tipo descrito no artigo 146 do Código Penal. Não se deve confundir esta assertiva com a prescrição contida no mesmo artigo 146, que estabelece não haver crime diante da "intervenção médica ou cirúrgica, sem o consentimento do paciente ou de seu representante legal, se justificada por iminente perigo de vida”.

Neste caso, como bem situa Nelson Hungria (1997, p. 176), a intervenção só é legitimada quando se mostrar "necessária, urgente e inadiável” para afastar risco de vida concreto, passível de ser debelado através do procedimento. Haverá, portanto, o crime se, em razão da abstenção da conduta, ainda que prevista, a morte apenas ocorra após período mais ou menos prolongado de sobrevivência. Luiz Regis Prado (2010, p. 268), na mesma linha, acrescenta que a situação de perigo de vida há que se revelar através de sintomas indiscutíveis e inequívocos de ameaça de sua extinção. Ainda assim, insiste que se trata de estado de necessidade justificante.

Em outras situaçóes de intervenção não consentida há uma violação do exercício da vontade autônoma do titular do bem jurídico individual que deve ser considerada como subsumida ao mesmo artigo 146. No entanto, o Código Penal brasileiro, no mesmo referido dispositivo, ao tipificar o delito de constrangimento ilegal, excetua, expressamente, a "coação exercida para impedir suicídio". Portanto, confere-se, legalmente, prevalência à proteção do bem jurídico vida, ainda que contra a vontade expressa do seu titular se não se tratar de situaçáo que configure estado de necessidade.

Constata-se, deste modo, a dificuldade, em face da complexidade da normatização do consentimento, de uma interpretação aligeirada da Resolução 1.995, a qual requer 
uma compreensão cuidadosa e harmônica com o ordenamento jurídico nacional. Percebe-se, assim, que o testamento vital que estabeleça, como desejo do paciente, a prática de eutanásia ou outros comportamentos lesivos que não tenham como intuito afastar um sofrimento maior, encontrará obstáculos à sua eficácia plena nos ditames estabelecidos no Código Penal brasileiro.

\section{Conclusões}

O testamento vital constitui forma de prestigiar a autonomia do indivíduo, dandolhe a oportunidade de, antecipadamente, deixar registrada sua vontade sobre os tratamentos que deseja ou não para si própria numa fase de incapacidade decisória. É, portanto, um consentimento prospectivo que decorre de necessidades da contemporaneidade quando a assistência de saúde de massa impede o estabelecimento de vínculo de proximidade entre medico/paciente, permitindo que aquele saiba como conduzir o tratamento deste de acordo com seus valores, crenças e desejo. Além disto, na sociedade atual, ao tempo em que se pode prolongar a vida, pode-se também recorrer ao uso de tecnologias sofisticadas, invasivas e dolorosas que contribuem para a desumanização da existência, sobretudo quando são usadas desproporcionalmente em doentes terminais. Torna-se, então, necessário o fortalecimento de princípios éticos que situem o indivíduo como sujeito moral em face de outro sujeito moral, o que significa importante avanço na ciência médica que se regia pelas prescriçóes hipocráticas as quais, embora propusessem o bem e vedassem o mal ao paciente, não tomavam em consideração sua vontade.

A Resolução 1.995/2012 do CFM, todavia, deve ser interpretada conforme o ordenamento jurídico nacional, incluindo-se, nesse sentido, a Resolução 1.805/2006, também do CFM, impedindo-se que seja entendida como um recurso que tudo permite àquele que é titular do bem jurídico vida.

A autonomia para afastar a proteção da norma é representada no Direito Penal pelo consentimento, construção que sofre limitaçôes jurídicas, na medida em que o direito visa à realizaçáo do indivíduo numa ordem coletiva. Desta forma, a possibilidade de disposição sobre determinados bens jurídicos tem sido vedada pela maioria dos ordenamentos jurídicos dos estados ocidentais, entendendo-se, dentre estes a vida cuja violação constitui um tabu.

Há situaçôes nas quais, todavia, não se trata de proteção da vida como bem, mas tão só de sua indevida protelação sem qualidade, uma vez que ao sofrimento da doença soma-se o sofrimento desproporcional da intervenção. Nestes casos, com vistas a preservar a liberdade e a dignidade da pessoa, tem-se permitido que ela possa escolher livremente se deseja ou não ser submetida a processos de obstinaçáo terapêutica, evitando-se sua reificação. A ortotanásia é um direito do enfermo (para quem cuidados paliativos até a morte 
não podem faltar) cujo reconhecimento pela Resolução CFM 1.995/2012 constitui uma vitória da capacidade de autodeterminação sobre o paternalismo incapacitante.

\section{Referências}

ALEMANHA. Código Penal de 1871 com a Reforma de 1998. Disponível em: https:// www.unifr.ch/ddp1/derechopenal/obrasjuridicas/oj_20080609_13.pdf Acesso em: 20 de maio de 2015.

ARGENTINA. Lei no 26.742. Disponível em: http://www.infoleg.gov.ar/infolegInternet/anexos/195000-199999/197859/norma.htm Acesso em 20 de maio de 2015.

. Lei 26.994. Código Civil y Comercial de la Nación Argentina. Disponível em: http://www.infoleg.gob.ar/infolegInternet/anexos/235000-239999/235975/ norma.htm Acesso em 20 de maio de 2015.

ANDRADE, Manuel da Costa. Consentimento e Acordo no Direito Penal. Coimbra: Editora Limitada, 1991.

BEAUCHAMP, Tom. Methods and principles in biomedical ethics. J Med Ethics 2003;29:269-274 doi:10.1136/jme.29.5.269. Accepted 8 July 2003. Disponível em: http://jme.bmj.com/content/29/5/269.full Acesso em: 14 de maio de 2015.

; CHILDRESS, James. Princípios de Ética Biomédica. São Paulo: Loyola; 2002.

CABETTE, Eduardo Luiz Santos. Eutanásia e ortotanásia - comentários à Resolução 1.805/06 CFM - aspectos éticos e jurídicos. Curitiba: Juruá, 2013.

CASABONA, Carlos María Romeo. La genética y la biotecnología en las fronteras del derecho. Acta Bioethica 2002; año VIII, nº 2. Disponível em: http://www.scielo.cl/ pdf/abioeth/v8n2/art09.pdf Acesso em: 15 de maio de 2015.

COMISSÃO TEMPORÁRIA DE ESTUDO DA REFORMA DO CÓDIGO PENAL.

Parecer: sobre o Projeto de Lei do Senado no 236, de 2012, que reforma o Código Penal Brasileiro. Brasil, 2013. Disponível em: http://www.senado.leg.br/atividade/ materia/getPDF.asp?t=142673\&tp= Acesso em: 25 de maio de 2015.

FRANÇA. Code de la santé publique. Version consolidée du code au 9 mai 2015. Edition: 2015-05-17. Disponível em: http://codes.droit.org/cod/sante_publique.pdf Acesso em: 20 de maio de 2015.

GUIMARÃES, Marcello Ovidio Lopes. Eutanásia: novas consideraçôes penais. Leme: J.H. Mizuno, 2011.

HUNGRIA, Nelson. Comentários ao Código Penal. 6.ed. atualizada por Heleno Fragoso. Rio de Janeiro: Forense, 1977. 
. Revista dos Tribunais. - Ano 43, v. 221, mar. 1954.

KOTTOW, Miguel. Las multiplas facetas de la decision y el consentimiento informados. participación informada en clínica e investigacíon bioética. Bogotá: Unesco, 2007.

LIPPMANN, Ernesto. Testamento vital - o direito à dignidade. São Paulo: Matrix, 2013.

MÉXICO. Decreto Número 82 - Ley de Voluntad Anticipada del Estado de México. Publicação: 03 de maio de 2013. Disponível em: http://www.edomex.gob.mx/legistelfon/doc/pdf/ley/vig/leyvig191.pdf Acesso em: 20 de maio de 2015.

MÖLLER, Letícia Ludwig. Direito à morte com dignidade e autonomia - o direito à morte de pacientes terminais e os princípios da dignidade e autonomia da vontade. Curitiba: Juruá, 2012.

PESSOA, Laura Scalldaferri. Pensar o final e honrar a vida: direito à morte digna. São Paulo: Saraiva, 2013.

PIERANGELI, José Henrique. O consentimento do ofendido - na teoria do delito. 3. ed. São Paulo: Revista dos Tribunais, 2001.

POPE, Thaddeus Mason. The Maladaptation of Miranda to Advance Directives: A Critique of the Patient Self-Determination Act. Health Matrix: Journal of Law-Medicine, Vol. 9, No. 1, Winter 1999. Disponível em: SSRN: http://ssrn.com/abstract $=174749$. Acesso em 27 de maio de 2015.

PORTUGAL. Código Penal de 1995. Procuradoria-Geral distrital de Lisboa, Ministério Público. disponível em: http://www.pgdlisboa.pt/leis/lei_mostra_articulado.php?ni$\mathrm{d}=109$ \& tabela=leis Acesso em: 20 de maio de 2015.

PRADO, Luiz Regis. Curso de Direito Penal brasileiro: Parte especial. 9.ed. São Paulo: Revista dos Tribunais, 2010.

REALE JUNIOR, Miguel. Testamento vital. Caderno Espaço Aberto. O Estado de S. Paulo, 4 de maio de 2013.

ROXIN, Claus. Derecho Penal: Parte General. Tomo I. Fundamentos. La estructura de la teoria del delito. 2. ed. Trad. Diego-Manuel Luzón Peña; Miguel Díaz y García Conlledo; Javier de Vicente Remesal. Madrid: Civitas, 1997.

. A proteçáo da vida humana através do direito penal. Trad. Luís Greco. Disponível em: mundojuridico.adv.br. Acesso em: 2 de abril de 2006.

SÁ, Maria de Fátima Freire de; MOUREIRA, Diogo Luna. Autonomia para morrer: eutanásia, suicídio assistido e diretivas antecipadas de vontade. Belo Horizonte: Del Rey, 2012. 
SANTORO, Luciano de Freitas. Morte digna - o direito do paciente terminal. Curitiba: Juruá, 2012.

SILVA, Mônica Neves Aguiar da. Modelos de autonomia e sua (in)compatibilidade com o sistema de capacidade civil no ordenamento positivo brasileiro: reflexóes sobre a Resolução 1995/2012 do Conselho Federal de Medicina. XXII Encontro Nacional do CONPEDI / UNICURITIBA. Tema: 25 anos da Constituição Cidadã: Os Atores Sociais e a Concretização Sustentável dos Objetivos da República. Organização CONPEDI/ UNICURITIBA; Coordenadores: Elcio Nacur Rezende, Francisco Cardozo Oliveira, Luciana Costa Poli. - Florianópolis: FUNJAB, 2013 : Curitiba, PR. Disponível em: http://www.publicadireito.com.br/publicacao/unicuritiba/livro.php?gt=148 Acesso em: 15 de maio de 2015.

SOUSA, Deusdedith. Revista dos Tribunais. - Ano 83, v. 706, ago. 1994.

VIEIRA, Mônica Silveira. Eutanásia: humanizando a visão jurídica. Curitiba: Juruá, 2012.

VILLAS-BÔAS, Maria Elisa. Da eutanásia ao prolongamento artificial: aspectos polêmicos na disciplina jurídico-penal do final de vida. Rio de Janeiro: Forense, 2005.

TRIBUNAL REGIONAL FEDERAL DA PRIMEIRA REGIÃO, 1a VARA FEDERAL DE GOIÂNIA, Açáo Civil Pública 0001039-86.2013.4.01.3500. Disponível em: http://processual.trf1.jus.br/consultaProcessual/processo.php Acesso em 20 de maio de 2015 . 